\title{
Optimizing Technology in Mobile Financial Services: User experiences and expectations in Ghana
}

\author{
Nana Akosah Sarpong \\ National Communications Authority \\ KIA, 6 Airport By-pass Rd \\ Accra
}

\author{
Mathias Agbeko \\ University of Education, Winneba \\ Department of ICT Education \\ P. O. Box 25 \\ Winneba - Ghana
}

\begin{abstract}
The mobile phone technology has been used to solve problems through various innovative ways of which Mobile Financial Services (MFS) is inclusive. As the world is becoming populated, attention has been drawn to how technology could help solve problems. One of such innovations is mobile financial services. In the case of Ghana, mobile financial service has now gained its way through many businesses and individuals as well. The aim of this research therefore is to evaluate MFS provision in Ghana by looking at its awareness and usage, customer satisfaction level, challenges and opportunities available. One hundred and fifty (150) respondents partook in this research work and analysis was done using SPSS. From the research, it was identified that people still have a lot of expectations for MFS provisioning in Ghana and these future desires which include foreign exchange services, ATM transactions in MFS, online shopping and online payments must be harnessed by MFS providers to satisfy the customer and protect their market share. Also, liaising with the banks can promote MFS transactions; and the ability of operators to ensure a stable network for the growth of MFS in Ghana. Through industryled initiatives, including partnerships with banks and other third parties, MFS providers can enhance the customer experience and reaching scale to evolve the sector to a new phase of maturity in Ghana. Eight different recommendations were made based on user experience in this paper.
\end{abstract}

\section{Keywords}

Mobile financial services; MFS; mobile money; customer satisfaction; mobile technology; awareness; agent; network operators; customer; providers; challenges.

\section{INTRODUCTION}

The use of mobile phones emanated as the world was becoming a global village. Mobile phones became a tool for this advancement. They were used in all other aspects such as dissemination of information among people living in different countries, for trading and others [14]. As the world was becoming populated, attention was drawn to how technology could help solve problems such as long queues in banks and also trading with people afar and near.

The introduction of mobile telecommunications and later, the adoption of mobile phones to provide financial services to the public through existing merchant infrastructure within local communities helped leverage the ubiquity of mobile phones as a means to provide access to financial services to the broadest range of consumers. Mobile money (m-money) offers a possible model for extending the benefits of financial services to a much wider section of the community [11]. Thus, mobile phone usage has become very advantageous to many people especially businessmen and traders.
The coming of mobile financial services was introduced at the turn of the 21st century when rapid changes gripped the banking environment [10]. According to [10], deregulation, harmonization, increased competition by new players from the non-banking sector, product innovations, globalization, technological advancements and digitalization led to a market situation where competition for customers became intense. This resulted in the banks developing innovative service products and offering a wider range of financial services through multiple channels, one of which was a wireless delivery channel available via mobile phones and Personal Digital Assistants (PDA's). Mobile financial services came to be considered as an important innovation in the banking sector.

From 2011, the Federal Reserve Board's Division of Consumer and Community Affairs of the United States conducted its first Survey of Consumers' Use of Mobile Financial Services and concluded that the use of mobile financing is increasing over time [5]. In that same report, the outcome of their research showed that, 33 percent of all mobile phone owners have used mobile banking in the past 12 months, up from 28 percent a year earlier. 51 percent of smartphone owners have used mobile banking in the past 12 months, up from 48 percent a year earlier. 12 percent of those mobile phone users who are not currently using mobile banking thought that they will probably use it within the next 12 months.

Similarly, according to the Inter Media study of households in Tanzania, the rate of m-money use is highest among urban and banked households, and households living above the poverty line. The Dar-es-Salaam region has the highest percentage of households with m-money users at 75 percent, and Kilimanjaro has the second largest percentage of households that use m-money, 58 percent of the region's population, [8].

In the case of Ghana, a mobile financial service has now gained its way through many businesses and individuals as well. Ghana's Tigo Cash was adjudged the "Best Mobile Money Product in West Africa" at the 2013 Kalahari Awards in Lagos, Nigeria [3]. The platform floated an estimated GH $\not 11$ million every day equivalent to over 2 million dollars and it recorded almost a million transactions every month. Previously, only a few individuals accepted this financial service. Now, many people have accepted the mobile transaction business and many issues have emanated from it.

Ghana currently has four of its telecommunication operators in this mobile transaction business namely, Airtel Money, Tigo Cash, MTN mobile money and Vodafone cash. Technology cannot be left out in the financial sector since in the last few years, it has revolutionized how people handle 
financial matters in the developing world. Especially since the great success of the deployment of M-Pesa, a mobile money platform provided by a mobile network operator in Kenya, banking through mobile phones and retail outlets has come to the center of attention. This success story has travelled all over the world and through that, the industry handling money through mobile phones has expanded heavily over the last few years [11]. In the beginning, these services mainly concentrated on transferring money from person to person through a mobile phone; but due to its expansion, it has attracted a wide range of different players seeking business opportunities. As a result, the accumulation of funds with the help of a mobile phone - mobile savings - is brought more into the focus [7].

This research is focused on giving an overview of the various mobile money services implemented in Ghana, and evaluating it as well. In particular, attention is given to how we can harness opportunities available in the mobile money sector.

\subsection{Research questions}

The study seeks to answer the following research questions:

1. What is the extent of awareness and usage of MFS in Ghana?

2. What is the extent of user satisfaction of MFS in Ghana?

3. What are the challenges of mobile financial services transactions in Ghana?

4. What opportunities are available to explore?

\section{LITERATURE REVIEW}

Mobile Financial Services (MFS) simply means the use of a mobile phone to access financial services and execute financial transactions [17]. Mobile financial services is not intended to replace today's banking model, but rather, to supplement it and to allow more people to access and participate in financial services. Telecommunication companies have a unique advantage in bringing mobile financial services to the people who traditional banks have difficulty reaching.

Recent research works have identified factors that contribute to Mobile Financial Services (MFS) as:

- $\quad$ Challenges of MFS

- $\quad$ Benefits of MFS to countries

\subsection{Challenges of MFS}

An empirical study from other scholars shows that the challenges on mobile financing include demographic factors, technological challenges, customer trust, customer willingness and socioeconomic factors. The Financial Inclusion Tracker Surveys Project [9] conducted a survey on mobile money in Tanzania. They found out that the more educated individuals are, the more likely they are to use m-money and that those with no formal education and older individuals $(55+)$ have the lowest rates of m-money adoption. The study further found out that the top two reasons for not using m-money were, lack of awareness about the services (13\%) and insufficient understanding of m-money (12\%). Customer's trust for the service is another challenge. According to [19], customer's trust is essential and will determine if consumers will use mobile financial transactions. [16] also admits that competence and integrity have significant effects on attitude, while perceived benevolence is insignificant. Therefore, if customers believed the mobile banking firm is able to develop effective service delivery strategies and provide adequate protection from fraud and violation of privacy, then adoption (or continue-to-use) intentions will have increased. Since mobile banking was relatively new, associated perceptions of competence was not great, and that was also a challenge facing the adoption of mobile financial services. The mobile money transaction involves two parties; the giving party and the receiving party. These two parties interact through the transfer of funds and also the payment of certain services. Without trust it is impossible to do such transactions among the two parties. According to [12] another specific and important factor influencing the acceptance of mobile services is trust. In support of the above statement, [2] and [13] suggested that willingness of the customers to doing financial transaction with their mobile phone was significantly associated with their level of trust. Technical issues were that registering for m-money was difficult; more than one-third said they had to wait a "long time" before the account was active and urban users experienced the longest median waits.

\subsection{Benefits of MFS to countries}

\subsubsection{Ghana}

It is used for receiving remittances and as a saving mechanism. Findings show that mobile money has improved households' ability to share risk in money transfers and also create a secure "pseudo-savings" account, where individuals can deposit smaller savings amounts for more immediate needs [1].

\subsubsection{Pakistan}

A mobile financial service provides easy accessibility to banking services that have previously been unavailable. The costs of the services are typically lower, transactions can be made instantly from anywhere, and customers no longer need to be so reliant on cash. Increased financial inclusion will lead to Pakistani GDP growth of 3\% by 2020 primarily through increased entrepreneurship [4].

\subsubsection{Malaysia}

Financial inclusion in Malaysia has made significant strides over the last decade, as today's statistics show that 80 percent of Malaysian adults are considered financially included [6].

\subsubsection{Hungary}

In 2014, Mauritius Telecom partnered with the Mauritius Revenue Authority and the State Bank of Mauritius to enable income tax payments via mobile for Orange Money customers. The report indicates that for the 2014 E-Filing season, the Mauritius Revenue Authority reported more than 123,000 returns received electronically (using mobile devices or online), representing a $12 \%$ increase as compared to the 2013 filing season [18].

\subsubsection{Kenya}

Most users of mobile money service in western Kenya use it as a social and economic tool through which they create relationships by sending money as gifts. Such gifts could be either social gifting, assisting friends and relatives, organizing savings groups or contributing to ceremonies and funerals [15].

\section{METHODOLOGY}

The approach used in this study was both quantitative and qualitative descriptive approach. Purposive sample technique was used to sample 150 users of mobile phones whom we presume will use it for mobile financial transactions. The study was based in the Greater Accra region and some parts of Eastern region. Greater Accra was selected as the main data 
collection site because it houses the head office of each of the Telecommunication companies where we have mobile financial transactions taking place in Ghana. Therefore, it would be easier to get customers to answer questionnaires easily when they come along to patronize the services. Eastern Region is of proximity to Accra and the two regions share borders on several cardinals, that was why it was also selected.

Data was mainly obtained from primary sources. Data collection approach was in the form of questionnaires which were administered to the customers of MFS who have subscribed to Tigo Cash, MTN mobile money, Airtel money, and Vodafone Cash. The focus was on the challenges they face in their usage of MFS and how satisfied they are with the services provided by the various operators as well as what they expect to be done based on how innovative MFS can be. The researchers personally distributed the questionnaires, explained, sought consent and retrieved the filled-in questionnaires.

Due to the descriptive nature of the study, simple questions demanding categorical responses were used to elicit responses for analyses. These questions sought to identify the mobile users' views about their access, use and satisfaction of Mobile Financial Services. The researchers also used a simple Satisfaction Scale to measure the user's satisfaction with the MFS, its duration, network provider, and transactional charges. This four-item measure developed by the researchers required participants to respond to items such as "I am satisfied with MFS" and "I am ok with transactional charges" using a 5-point Likert scale ranging from 1 (very dissatisfied) to 5 (very satisfied). The Cronbach's Alpha was utilized to test for the reliability of the scale and the coefficient alpha obtained for this measure was 0.61 . This gives an indication of a high internal consistency of the developed four-item measure. When the item "I am ok with transactional charges" is deleted however, the Alpha measure increases to 0.85 which indicates an even higher consistency.

A conclusion can therefore be drawn that, though that particular item does not necessarily measure satisfaction, it is important in determining the dissatisfaction of MFS users.

A Trust Scale was used to measure the user's trust of MFS transactions, security, convenience and preference over banking services. This four-item measure also developed by the researchers required participants to respond to items such as "I trust MFS transactions" and "MFS is very convenient and easy to use" using a 5-point Likert scale ranging from 1 (strongly disagree) to 5 (strongly agree). A Cronbach's Alpha coefficient of 0.775 obtained for this measure indicates a consistent nature of the items in the scale.

\section{DISCUSSION}

\subsection{Awareness and usage of mobile financial services}

Concerning awareness and use of MFS, $92 \%$ of the respondents are aware of MFS whiles $72 \%$ said they have received money through this service. This relatively high level of awareness could be indicative of effective advertising and market entry by the MFS providers. Though awareness does not necessarily indicate usage, the proportion of respondents who assert to receiving money through MFS (72\%) is quite high and affirms the growing market of MFS in Ghana. Table 1 below gives the cross-tabulation of the awareness and usage.

Table 1: Cross Tabulation of Awareness against Usage of MFS

\begin{tabular}{|c|c|c|c|c|c|c|c|}
\hline & & \multicolumn{2}{|c|}{$\begin{array}{l}\text { Are you aware of mobile } \\
\text { financial service? }\end{array}$} & \multirow[t]{2}{*}{ Total } & \multicolumn{2}{|c|}{$\begin{array}{c}\text { Have you ever received money } \\
\text { through this service? }\end{array}$} & \multirow[t]{2}{*}{ Total } \\
\hline & & Yes & No & & Yes & No & \\
\hline \multirow{2}{*}{ Gender } & Male & $72(92 \%)$ & $6(8 \%)$ & 78 & $57(73 \%)$ & $21(27 \%)$ & 78 \\
\hline & Female & $66(92 \%)$ & $6(8 \%)$ & 72 & $60(83 \%)$ & $12(17 \%)$ & 72 \\
\hline \multicolumn{2}{|c|}{ Total } & 138 & 12 & 150 & 117 & 33 & 150 \\
\hline
\end{tabular}

From Table 1 above, it can be observed that among both males and females, an equal proportion (92\%) of the population are aware of MFS; thus, the level of awareness has no gender barriers. Again, the results indicate that when it comes to usage, $73 \%$ of males have received money through the service at a point in time whereas $83 \%$ of females have ever received money through the service. The seemingly higher patronage by females could be because in the typical traditions of Ghana, males are expected to cater for the needs of their female dependents. The monies received could therefore be remittances sent by males. There was however no counter question to prove if males send more money through the service than females do.

\subsection{Reliability and ease of use}

The responses in Table 2 below gives an indication that the traditional banking system still has a strong arm in terms of sending and receiving money, even though MFS as an emerging market has seen upward trends in recent times. More people, $46 \%$ see the bank to be reliable in terms of receiving and sending money, whiles $52 \%$ believe the banks to be more secured and convenient for one to receive and send money in comparison to the $36 \%$ who see mobile money as secured and convenient. A gap is here identified in the perceived security and convenience of these two services, which will have an effect on the adoption of mobile financial service in the Ghanaian market. The security of MFS has in recent times been questioned as more and more fraudulent activities pervades the mobile money space. The authentication and authorization of users; both the sender and the recipient should be taken seriously especially when sending money so that it does not end up into the wrong wallet of a recipient. Again, the MFS providers should continue to sensitize their users through public education and short message service (SMS) on the ploys used by these criminals in retrieving cash from unsuspecting customers. The security issue could also be an explanation why $54 \%$ of the respondents do intend to make use of the bank to conduct financial transactions in the near future instead of MFS. They have the fear of losing their savings. This should be seen by the MFS providers as a further threat to their young market. 
Table 2: Reliability and Ease of use of MFS

\begin{tabular}{|c|c|c|c|c|c|c|}
\hline \multirow[t]{2}{*}{ Financial Service Providers } & \multicolumn{2}{|c|}{$\begin{array}{l}\text { Which of the following is } \\
\text { more reliable for you to } \\
\text { receive and send money? }\end{array}$} & \multicolumn{2}{|c|}{$\begin{array}{l}\text { Which of these is more secured } \\
\text { and convenient for you to receive } \\
\text { and send money }\end{array}$} & \multicolumn{2}{|c|}{$\begin{array}{l}\text { Which of these do you intend to } \\
\text { make use of more in the near } \\
\text { future to conduct your financial } \\
\text { transactions? }\end{array}$} \\
\hline & Frequency & Percent & Frequency & Percent & Frequency & Percent \\
\hline Bank & 69 & 46.0 & 78 & 52.0 & 81 & 54.0 \\
\hline Manual & 0 & 0.0 & 0 & 0.0 & 3 & 2.0 \\
\hline Money transfers & 15 & 10.0 & 18 & 12.0 & 3 & 2.0 \\
\hline Mobile money & 66 & 44.0 & 54 & 36.0 & 63 & 42.0 \\
\hline Total & 150 & 100.0 & 150 & 100.0 & 150 & 100.0 \\
\hline
\end{tabular}

\subsection{Satisfaction}

Satisfaction can be viewed as an individual's expectation in comparison to what the MFS actually delivers. Analyzing the items individually, it can be observed that a higher proportion of respondents expressed satisfaction with all the items in the scale. Aggregating "satisfied" and "very satisfied" scores, $68 \%$ expressed satisfaction with MFS in general; whiles 58\% are satisfied with the duration of the MFS transactions. $60 \%$ are satisfied with their network providers but only a combined
$36 \%$ are satisfied with transactional charges. However, the aggregated dissatisfaction levels are 10\%, 12\%, 16\% and 34\% respectively. It can be noted that more people expressed dissatisfaction with the transactional charges, that is to say $34 \%$ are not okay with the transactional charges. Thus, the network or MFS providers must take good note and reduce the charges or justify the reasons for these charges to make it more acceptable to the users.

Table 3: Satisfaction in using MFS

\begin{tabular}{|c|c|c|c|c|c|c|c|c|}
\hline \multirow[t]{2}{*}{ Scale } & \multicolumn{2}{|c|}{$\begin{array}{l}\text { I am satisfied with Mobile } \\
\text { Financial Service (MFS) }\end{array}$} & \multicolumn{2}{|c|}{$\begin{array}{l}\text { I am satisfied with the } \\
\text { duration of MFS }\end{array}$} & \multicolumn{2}{|c|}{$\begin{array}{l}\text { Rate my MFS network } \\
\text { provider }\end{array}$} & \multicolumn{2}{|c|}{$\begin{array}{c}\text { I am okay with transactional } \\
\text { charges }\end{array}$} \\
\hline & Frequency & Percent & Frequency & Percent & Frequency & Percent & Frequency & Percent \\
\hline Very dissatisfied & 6 & 4.0 & 6 & 4.0 & 12 & 8.0 & 9 & 6.0 \\
\hline Dissatisfied & 9 & 6.0 & 12 & 8.0 & 12 & 8.0 & 42 & 28.0 \\
\hline Neutral & 33 & 22.0 & 45 & 30.0 & 36 & 24.0 & 45 & 30.0 \\
\hline Satisfied & 84 & 56.0 & 66 & 44.0 & 75 & 50.0 & 45 & 30.0 \\
\hline Very satisfied & 18 & 12.0 & 21 & 14.0 & 15 & 10.0 & 7 & 6.0 \\
\hline Total & 150 & 100.0 & 150 & 100.0 & 150 & 100.0 & 150 & 100.0 \\
\hline
\end{tabular}

\subsection{Transactions done using mobile financial services in Ghana}

A summary of the open comments identified some trends which will enable us know which transactions people use MFS for, what can be done to improve and make MFS more attractive and what other transactions users would like to make with MFS.

\subsubsection{MFS Transactions}

MFS users usually engage in the following transactions:

- Sending and receiving funds

- Buying airtime

- Deposits into wallets

- Paying utility bills
- Buying data for oneself and gift data for others

- Payment of DSTV bills

- Checking balance

The two most common transactions that run through the responses were airtime top up and sending and receiving money.

\subsection{Challenges of MFS transactions in Ghana}

Providing Mobile Financial Services have not been without challenges. The trust, security, convenience and preference for MFS were measured on a scale to try and determine the possible weaknesses in the provision of MFS. It was observed from Table 4 below that trust of MFS services, security of MFS, and convenience of MFS had means ranging between 
3.58 and 4.08 , which are above the average score of 3 . The standard deviations below 1.0 also follow suit to give an indication of trust in MFS services. However, when it comes to preference for MFS services over traditional banking services, the reverse of the result on trust holds true. This item had a mean of 2.96 and a standard deviation greater than 1 , indicating that respondents do not prefer MFS to traditional banking services. This again gives an upper arm to the banks while creating a weakness for MFS providers.

Table 4: Descriptive Statistics for Trust in using MFS

\begin{tabular}{|c|c|c|c|c|c|}
\hline Item & $\mathrm{N}$ & Minimum & Maximum & Mean & Std. Deviation \\
\hline I trust MFS transactions & 150 & 1 & 5 & 3.80 & .751 \\
\hline I believe that MFS are safe and secured & 150 & 1 & 5 & 3.58 & .877 \\
\hline MFS is very convenient and easy to use & 150 & 2 & 5 & 4.08 & .848 \\
\hline $\begin{array}{c}\text { I prefer MFS over traditional banking } \\
\text { services }\end{array}$ & 150 & 1 & 5 & 2.96 & 1.134 \\
\hline Valid N (list wise) & 150 & & & & \\
\hline
\end{tabular}

By virtue of the responses, it can be deduced that users do not face any major challenges with MFS, apparently because they deem it relatively safe and secured, convenient and easy to use, and they trust MFS transactions. It will however be profitable to ascertain reasons for the preference of traditional banking services if MFS transactions are not problematic. If MFS transactions were to be time consuming, then that would have been a great challenge. From Figure 1 below, it can be observed that MFS transactions are relatively time efficient. Thus $60 \%$ of the respondents claim it takes them not more than 15 minutes to travel to an agent. $18 \%$ spend 16-30 minutes while $12 \%$ spend more than 30 minutes travel time.

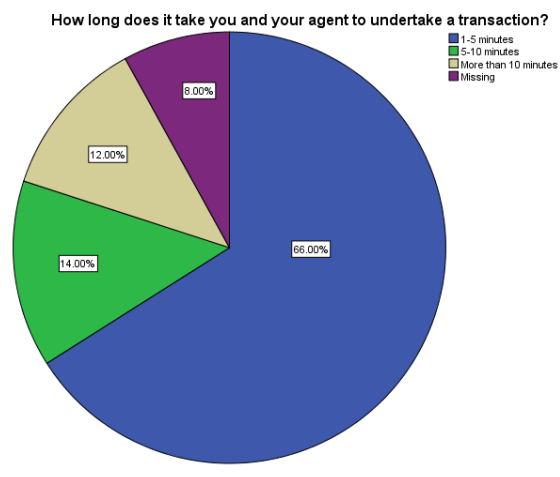

Figure 1: Transaction time

\section{CONCLUSION}

As seen from the research, MFS is a fast-growing industry, therefore to ensure continuous growth, operators should ensure that there is an effective improvement to the quality of their networks, to ensure smooth transactions and that liaising with the banks is also essential to the growth of MFS. The location of agent site should be taken into consideration as it has an effect on the usage pattern of customers. Mobile financial services can also be used as a means to bank the unbanked.
$10 \%$ of the respondents do not access an agent for MFS transactions.

With respect to the time spent on a transaction, a majority of the respondents $(66 \%)$ do not spend more than 5 minutes during a transaction as seen in Figure 2 below. 14\% spend 510 minutes, whiles $12 \%$ spend more than 10 minutes. $8 \%$ could not stipulate the time they spend in transacting a Mobile Financial Service. With an average travel and transaction time of 20 minutes, much time can be saved as compared to the average time one may spend at most banking halls in the country.

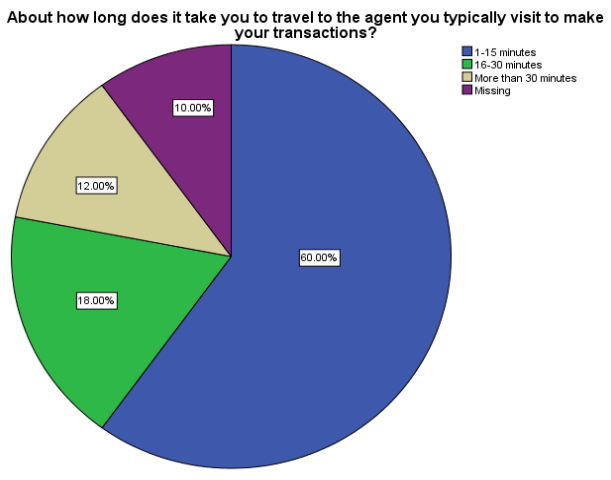

Figure 2: Travel time

\section{RECOMMENDATIONS}

In ascertaining how to make MFS more attractive, respondents stated their expectations as follows; which this research recommends that providers of MFS take note and implement or consider.

- Network operators should improve mobile network quality by avoiding unnecessary jams and delays in transactions - The provisioning of a stable mobile network will help alleviate the issue of delay in receiving money or doing transaction with one's phone and also 
avoid misunderstanding and complains between customers and providers. This is because the network must always be reliable to aid in fast transactions.

- Reduce the transaction charges or better still, eliminate transaction charges altogether (less transfer charges and no withdrawal charge) - Transaction charges when reduced will encourage more people to patronize MFS services since a lot of people are discouraged due to the charges attached, though they have interest in using MFS.

- Innovative advertising - Despite all the advertisements by the network operators, it seems more attention is given to the other value-added service products as compared to MFS. The growth of MFS will demand more innovative ways to attract customers like introduction of free day without transaction charges, giving free airtimes and gifts to customers who patronize the services can help maintain client and customer focus. Incentives should be given to customers for regular use of MFS and for keeping certain balances in their mobile wallets.

- Create a portal that allows you to transfer to your bank for further banking transactions - This will enhance the customer experience to reach a scale to evolve the sector to a new phase of maturity whereby most bank transactions can also be done with MFS especially in areas (rural areas) where banks are not in reach. It should be possible to deposit or receive money through MFS-bank transactions and vice versa. For societies where banks and financial institutions are already well interconnected, the challenges may be less than for those where systems are less interconnected. Different stakeholders including banks, other financial institutions, GSM firms as well as commercial outfits (who will receive payments via the mobile financial transaction system) should be involved and they all have to come together to consider how to interconnect the payment systems as seamlessly as possible.

- Transactions must be safe and secure (improve security features) - With the penetration of smart phones, our phones have become smarter, so have the criminals. Mobile viruses, malware, Trojans and rogue applications are all a threat to the success of mobile money services. Lack of consumer education allows criminals to elicit information from unsuspecting mobile money customers which is used in fraudulent activities. Therefore, it is imperative on mobile operators to work closely to provide greater levels of security and a safe mobile experience.

- $\quad$ Agent to Customer relation - Create more MFS stations with professional agents and also agents should have enough money when customers need to cash out. An ID card should not be required if the number is registered, this implies that operators should be able to find a way of making agents able to confirm subscriber identity through a short code. This will require an efficient and reliable database. Regular trainings for agents with the use of the technological platforms on which the MFS transactions are made are also necessary.

- An app should be created for smartphone users - As this is being implemented in other countries, the mobile money industry providers should be able to extend access to financial services beyond the reach of traditional financial institutions and creating apps for smart phones would really go a long way to help with increasing numbers of smart phone users which will in turn promote the growth of MFS.

- Economic impact needed - Also, increasing financial inclusion of a country will lead to growth in GDP through increased entrepreneurship as jobs are created through MFS

Another opportunity to strengthen the hold of MFS providers in Ghana's economy can be identified in this research. Respondents stated they would like to make these further transactions with MFS:

- Deposit into bank account

- Online payments/transactions

- $\quad$ Pay utility bills

- Shop online

- Exchange currencies

- Buy goods in shops

- Include MFS in ATM transactions (withdraw from ATMs)

These future desires should therefore be harnessed by the MFS operators to fully satisfy their customers and protect their market share. Also, the central bank can help with good policies to help regulate this service. In addition, since it runs on mobile technology, the Quality of Service (QoS) offered by service providers is also essential to the growth of this mobile money service and hence the telecom regulators can liaise with the central bank to ensure this.

\section{REFERENCES}

[1] Aker, J. C., \& Wilson, K. (2013, January). Can mobile money be used to promote savings? Evidence from Northern Ghana.

[2] Atuyota-Ejughemre, K. (2009). Promoting Mobile Financial Transactions: A Case Study Zain Sierra Leone.

[3] Biztechafrica. (2013, February 5). Tigo Cash named Best Mobile Money Product in West Africa. Retrieved from BizTechAfrica:https://www.biztechafrica.com/article/tig o-cash-named-best-mobile-money-product-westafr $/ 5375 /$

[4] Boston Consulting Group. (2011). The Socio-economic impact of mobile financial services: Analysis of Pakistan, Bangladesh, India, Serbia and Malaysia.

[5] DCCA. (2014). Consumers and Mobile Financial Services 2014. Washington, DC: Board of Governors of the Federal Reserve System.

[6] Demirguc-Kunt, A., Klapper, L., \& Randall, D. (2013). Islamic Finance and Financial Inclusion: Measuring Use of and Demand for Formal Financial Services among Muslim Adults. The World Bank.

[7] Demombynes, G., \& Thegeya, A. (2012). Kenya's mobile revolution and the promise of mobile savings. The World Bank.

[8] FII. (2014). Tanzania Quicksights Report FII Tracker Survey Wave 1. Nairobi: InterMedia. 
[9] FII InterMedia. (2013). Financial inclusion insights tracker survey Kenya. Washington, DC: InterMedia.

[10] Gonzalez, F. (2011). Innovation for the 21st Century Banking Industry. In F. e. Gonzalez, Innovation, Perspectives for the 21st Century (pp. 10-21). Spain: BBVA.

[11] GSMA. (2015). 2015 State of the Industry Report Mobile Money. London: GSMA.

[12] Kaasinen, E. (2005). User acceptance of mobile services: Value, ease of use, trust and ease of adoption.

[13] Kim, D. J., Ferrin, D. L., \& Rao, R. H. (2008). A trustcustomer making, model in electronic commerce: the role of trust, perceived risk, and their antecedents. Decision support systems, 544-564.

[14] Kofigah, S. K. (2010). Mobile payments system: The challenges to its adoption in Ghana and what can be done to make it catch on? Doctoral dissertation.
[15] Kusimba, S., Chaggar, H., Gross, E., \& Kunyu, G. (2013). Social networks of mobile money in Kenya. Institute for Money, Technology \& Financial Inclusion (IMTFI).

[16] Lin, H.-F. (2011). An empirical investigation of mobile banking adoption: The effect of innovation attributes and knowledge-based trust. International journal of information management, 252-260.

[17] MFSWG. (2012, July). Mobile Financial Services: Basic Terminology. Bangkok, Thailand: Alliance for Financial Inclusion.

[18] Scharwatt, C., Katakam, A., Frydrych, J., Murphy, A., \& Naghavi, N. (2014). 2014 State of the Industry - Mobile Financial Services for the Unbanked . London: GSMA.

[19] Siau, K., \& Shen, Z. (2003). Building Customer Trust in Mobile Commerce. Communications of the ACM, 91-94. 